\title{
Alcohol Gels: Causing More Harm Than We Thought
}

\author{
Mathew A Diggle ${ }^{1}$ and Andrew Kemp ${ }^{2 *}$ \\ ${ }^{1}$ Department of Clinical Microbiology, Nottingham University, UK \\ ${ }^{2}$ University of Lincoln, $U K$
}

*Corresponding author: Andrew Kemp, Reader in Biology Sparkhouse Building, Uiversity of Lincoln Rope Walk, Lincoln, LN67DQ UK

To Cite This Article: Andrew Kemp. Alcohol Gels: Causing More Harm Than We Thought. Am J Biomed Sci \& Res. 2019-1(6). AJBSR.MS.ID.000557. DOI: 10.34297/AJBSR.2019.01.000557

Received: March 15, 2019 | Published: March 20, 2019

\section{Introduction}

Several pieces of a significantly important research have now come together to present a very different picture of the outcomes we can expect from the current doctrine on hand hygiene in our healthcare facilities. The new evidence, (one piece of which was produced by the BBC TV series "Twinsitutue"), shows beyond any doubt that alcohol gels have the capacity to not only increase the number of bacteria on skin, but to significantly change the species of bacteria that colonise the skin. Further, the species that is shown to replace the natural skin commensals, is a bacillus, this therefore carries an increase risk due to it's potential for significantly more harm [1].

When alcohol is applied to the skin on hands or the abdomen, two previous research papers, both demonstrate a significant increase in bacterial numbers over time on the hands, and another paper, showed similar results on the abdominal skin prior to surgery [2-4]. The conclusions of all three papers, was that based on bacterial numbers alone, alcohol needed to be combined with another antimicrobial to be of value over time when compared to other methods of skin sanitation. One of the papers looked at the potential to use alcohol after a persistent SiQuat had been used, showing improved results over alcohol alone. Unfortunately, in each of these papers, the authors were not able to look at the species of bacteria before and after the alcohol gel had been used. The BBC documentary programme "Twinsitutue", although scientifically inert, was able to demonstrate the change in bacterial species, to the much more harmful Bacillus species, which adds a new and worrying dimension to the picture of what is happening to skin and surface contamination in our healthcare institutions.

It is almost impossible to imagine how anyone could now sperate the bacterial number and species on skin to those on surfaces. Now that it is also proven beyond doubt that disinfectant resistance is inextricably linked to antibiotic resistance in some pathogenic bacterial species, this must significantly increase our levels of concern that we are following the best possible hand hygiene protocols [5-9]. In both of the hand hygiene research papers mentioned above, the conclusion included the potential to increase the frequency of alcohol gel application to ensure numbers of bacteria remained low. Unfortunately, now that we understand the species change, that appears to no longer be an option, and we must discount that assertion moving to the other recommendation, that alcohol has to be combined with another antimicrobial or replaced with either, more frequent hand washing and/or a different antimicrobial. There are multiple cases of fatality caused by various Bacillus species that are linked directly to the use of alcohol to sanitise skin.

Since 2016 the EU has given 4.7Bn Euros of European tax payers money to large pharmaceutical companies for the development of new antibiotics, with not a single cent going into the development of new tests or for new disinfectants, including skin disinfectants. This must beg the question "are pharmaceutical industry lobbyists really that successful at presenting their arguments?" or is something else unseen effecting this type of political decision. An important article published in the BMJ in December 2018 [10]. looked at how lobbying in Europe by large corporations had blocked safety checks on dangerous medical implants. Is the same type of lobbying blocking our ability to change current hand hygiene doctrine? Whilst it is commendable that tax payer's money is spent on research, surely academic institutions which are already paid for by governments, would present a far better value proposition, and be far better placed to make use of their inventions, by selling new product licenses to large pharmaceutical companies, returning at least some of the investment to the tax payer.

It appears to date, that the WHO, US CDC, and our governments have ignored the latest research data and evidence, and perhaps are also choosing to ignore a healthy dose of common sense. It is clear now that it is easier for these institutions to prefer zero inertia, rather than action. Perhaps they are hoping that as there is little or no lobbying on this subject from industry, patient groups or academia, that this will all simply go away with time. However, the growing body of evidence is now undeniable. For some there is 
already enough to advocate at the very least, immediate sesation of the use of alcohol gels. Unfortunately, still more frustration awaits as the lack of movement from the only institutions that can effect real change continues.

We must now, relook and reevaluate the most basic of healthcare interventions - our hand hygiene. This must now include not just the antimicrobial choice, but the frequency of use.

\section{References}

1. Mayr FB, Yende S, Angus DC (2014) Epidemiology of severe sepsis. Virulence 5(1): 4-11.

2. Kemp A, Hodgkinson V, Bugg A (2018) Alcohol gels: More harm than good? Clinical Services Journal 17(2): 44-46.

3. Kemp A, Hodgkinson V, Bugg A Alcohol gels, the end of an era? Clinical Services Journal 17(6): 52-54.
4. Kemp A, Hodgkinson V, Bugg A. Surgical Skin prep: What effect does it really have? Clinical Services Journal Op Theatre Supplement 30-34.

5. McDonnell G, Russel D (1999) Antiseptics and disinfectants: Activity, Action and Resistance. Clinical Microbiology Reviews 12(1): 147-179.

6. Ash R J, Iverson J L (2002) Antibiotic and disinfectant resistant bacteria in rivers of the United States. Department of Biology, Institute for Agriculture and trade policy, Washburn University, Topeka, KS.

7. Russell AD (1999) Bacterial resistance to disinfectants; present knowledge and future problems. Journal of Hospital Infection 43 Suppl: S57-68.

8. (2008) Microbiology Society Disinfectants can make bacteria resistant to treatment. Public release.

9. (2009) Live Science Staff Disinfectants Cause Some Bacteria to Adapt, Thrive. Live Science Health.

10. Bowers S, Cohen D (2018) How lobbying blocked European safety checks for dangerous implants. British Medical Journal 363: k4999. 